\title{
Design and Analysis of High Pressure Extractor with Supercritical
} Fluid

\author{
K. D. Joshi ${ }^{1}$, M. S. Kirkire ${ }^{2}$ \\ ${ }^{1}$ ME student, Department of Mechanical Engineering, \\ Finolex Academy of Management \& Technology, Ratnagiri, Maharashtra, India \\ ${ }^{2}$ HOD, Department of Mechanical Engineering, Finolex Academy of Management \& Technology, Ratnagiri, \\ Maharashtra, India
}

\begin{abstract}
Supercritical fluid extraction (SFE) of natural material with solvents like CO2, propane, butane, or ethylene is an important extraction process which allows the processing of plant material at low temperatures, hence limits thermal degradation, and avoids the use of toxic solvents. To achieve most effective, efficient and safe way to extract valuable constituent from natural botanicals at high pressure thorough design approach is a prime requirement. Various design parameters of equipment and chemical properties of supercritical carbon dioxide (SCCO2) can affect the quantity and quality of extract. Researchers had focused on behavior of physicochemical properties of the $\mathrm{SC}-\mathrm{CO} 2$, including density, diffusivity and viscosity which can be controlled by optimizing pressure and temperature of the extraction system. But that research study does not contain structural-design of equipment used for SFE. In this research, for SFE, Supercritical CO2 is considered as supercritical fluid as SC-CO2 is easily available, recyclable, non-flammable and non-poisonous. By considering food-grade application, high pressure extractor is designed and analyzed using FEA. Standard components are designed using ASME Section VIII Div. I and other components are designed using basic machine design concept. Special clamping system is designed for an extractor and is to be analyzed using FEA and for safety precautions rupture disk and relief valve is selected.
\end{abstract}

Keyword: Supercritical fluid extraction, extractor design, high pressure vessel, FEA.

\section{Introduction}

Extraction involves the separation of medicinally active portions of plant or animal tissue from the inactive or inert components using selective solvents in standard extraction procedures using proper/ suitable extraction equipment. For better quality of extracts, the development of new extraction techniques for the chemical and food industries has received a lot of attention. Now a days, supercritical fluid extraction is the most effective and efficient way to extract valuable constituent botanicals in which one component (the extractant) is separated from other (the matrix) using supercritical fluids that is $\mathrm{CO}_{2}$ as the extracting solvent. In an extraction unit, extractor, which is a pressure vessel working under a high internal pressure, is the one where exact extraction process is to be carried out. These pressure vessels can range from simple tubing to more sophisticated purpose built vessels with quick release fittings. Through design point of view, geometrical parameters also lead to adverse effect on SFE process; hence it is necessary to set-up a systematic approach for design and analysis of high pressure extractor with supercritical fluid which should also comply ASME code Section VIII Div. I.

\section{Literature Review}

Many researchers had focused on behavior of physicochemical properties of the SC-CO2, including density, diffusivity and viscosity which can be controlled by optimizing pressure and temperature of the extraction system. This is more inclined towards chemical and food engineering. The SFE process flow is also designed by some of researchers. Andrea Capuzzo, Massimo E. Maffei and Andrea Occhipinti [1] had studied the supercritical fluid extraction of plant flavors and fragrances. Their work describes the biological activity of SFE extracts by describing their some of chemical properties. The work also discusses the process modelling, mass-transfer mechanisms, kinetics parameters and thermodynamic by giving an overview of SFE potential in the flavors and fragrances arena. Researchers concluded that SFE can be considered a sound cleantech strategy to extract natural compounds with definite environmental friendliness. This is due to properties like non-toxic nature, highly pure, safe, cost effective, nonflammable and recyclable of SC-CO2. This study had focused in terms of chemical 
engineering and biological area. No procedure to design extractor is done; only process is defined using various applications. Hence there is a scope to design an Extractor under special purpose category. Mandana Bimakra, Russly Abdul Rahmana,b, Farah Saleena Taipa, Ali Ganjloob, Liza Md Salleha,d, Jinap Selamatc, Azizah Hamidc, I.S.M. Zaidulc [2]- As different methods of natural matter extraction have different extraction yield and efficiencies, SFE and conventional Soxhlet extraction techniques are compared to conclude the better technique of extraction. Supercritical $\mathrm{CO}_{2}$ extraction was tested to search for a faster and better extraction method consuming less solvent, especially those that are undesirable in food industry. Conventional soxhlet extraction (CSE) is not always acceptable for industrial applications due to long extraction time, large consumption of hazardous solvents and some other disadvantages. Therefore, supercritical $\mathrm{CO}_{2}$ extraction could be an alternative extraction method. C. Pronyk, G. Mazza [3] Literature is focused on SFE process flow and components involved in SFE process. Area of interest involves mass transfer rate, phase equilibria related to content in an extractor. Effect of processing parameters like flow rate and physical properties of material to be extract, bed length to diameter ratio on extraction process is discussed. There is no procedure to design extractor; only process parameters are discussed to improve yield. Frank Panzner, Braib R. Evans [4] had done the research on extraction of plant material by using carbon dioxide. They had filed a patent on supercritical fluid extraction by using carbon dioxide. Literature is focused on process of SFE and various components involved in SFE process in detailed. Though it involves various components used for extraction process, it does not include any design parameters G. N. Sapkale, S. M. Patil, U. S. Surwase And P. K. Bhatbhage [5] provides an understanding of basic knowledge about the Supercritical Fluid Extraction technique. The researchers explains about SFE, solvent verities and their properties, extraction unit and the equipments involved. The properties and behavior of supercritical fluid is explained. Though it gives brief about SFE technology, it does not include any parameters related to the design of an extractor. Vibha Porwal, Pallavi Singh, Devendra Gurjar [6] gives a comprehensive study on different methods of extraction of Gujava leaves. Researchers explains various types of extraction techniques like Soxhlet extraction, Ultrasound extraction, Steam distillation extraction and Supercritical extraction technique. The research is more inclined towards the pharmaceutical field hence the extraction process is studied through medical point of view which is for curing various health problems. In this research also, no geometrical parameters related to extraction equipment design are considered.

M. Angela, A. Meireless [7] - Various geometrical parameters are reported based on experimental data for various systems of type solid substratum $+\mathrm{CO}_{2}$. These geometrical parameters include extractor's volume, diameter, height etc. Author had performed the analysis for getting cost of manufacturing. No design aspects are involved in the work. Hence based on this cost optimization study best design parameters can be applied for SFE pressure vessel. Nitin Deshmukh, Rajkumar Patil [8] described a simple methodology based on ASME code is used to design pressure vessel to calculate maximum allowable working pressure (based on normal operating condition) and maximum allowable pressure (based on weakest part) using pressure vessel design manual. But no operational parameters are involved like type of fluid stored, for what purpose it can be used. Operational safety is not included like bursting or crack propagation. Scope for this can be like, by considering specific application, MAWP and MAP can be found out with safety parameters and corresponding design of pressure vessel can be performed. Tang Deyu Niu Huli Li Chunrun Fang Zongtao LvTao ZhaoJie [9] performed a whole fatigue analysis design about high pressure quick-open vessels on ANSYS. A new technique to design a quick opening or pressure vessel was designed by the researchers. A finite element model of the high pressure quick-open vessels was built using the limit element analysis

\begin{tabular}{|c|c|}
\hline \multicolumn{2}{|r|}{ Nomenclature } \\
\hline $\mathrm{D}_{1}$ & : Outer Diameter of main shell (mm) \\
\hline $\mathrm{R}$ & : Outer radius of main shell $(\mathrm{mm})$ \\
\hline $\mathrm{D}_{2}$ & : Inside diameter of main shell $(\mathrm{mm})$ \\
\hline $\mathrm{A}_{1}$ & $\begin{array}{l}\text { Area of cross-section of Cap Seating Cover } \\
\left(\mathrm{mm}^{2}\right)\end{array}$ \\
\hline $\mathrm{A}_{2}$ & $: \begin{array}{l}\text { Area of cross-section of Clamping system } \\
\left(\mathrm{mm}^{2}\right)\end{array}$ \\
\hline $\mathrm{P}$ & : Design Pressure $(\mathrm{Mpa})$ \\
\hline $\mathrm{S}$ & : Allowable stress for material (Mpa) \\
\hline $\mathrm{E}$ & : Welded Joint Efficiency \\
\hline $\mathrm{L}_{1}$ & : Crown radius for hemispherical head (mm) \\
\hline $\mathrm{L}_{2}$ & : Crown radius for torispherical head $(\mathrm{mm})$ \\
\hline$\tau$ & : $\quad$ Shear Stress for material (MPa) \\
\hline $\mathrm{t}_{1}$ & : Thickness of main shell $(\mathrm{mm})$ \\
\hline$t_{2}$ & $:$ thickness of cap seating cover $(\mathrm{mm})$ \\
\hline$t_{3}$ & : Thickness of cap (mm) \\
\hline $\mathrm{t}_{4}$ & : Thickness of clamping system (mm) \\
\hline$t_{5}$ & : Thickness of hemispherical end (mm) \\
\hline$t_{n}$ & Thickness of nozzle (mm) \\
\hline
\end{tabular}
software ANSYS and found that all conditions has been satisfied by pressure vessel. ASME Boiler and Pressure Vessel Code [10] - For the current required design of an extractor, ASME PV codes are implemented. Based on these codes high pressure vessel is designed. For various parts design and selection particular codes are used like UG-16 : The general design of pressure vessels and vessel parts, UG-21: Design Pressure, UG-23 : Maximum

6th National Conference RDME 2017, 17th-18th March 2017. 
Allowable Stress Values, UG-27 : Thickness of shell under Internal Pressure, UG-32 : Formed Head and Sections under Internal Pressure, UG-34 : Unstayed Flat Heads and Covers under Internal Pressure. Guibing Zhao [11] provides a knowledge about the safety systems. A brief about an easy method to design gas/vapor relief system with rupture disk is explained. In this research Introduction to emergency relief systems is involved. Function of each; valve and rupture disk is given in the literature. A simple methodology to design a relief system with rupture disk and valves is described. This paper aims to find the appropriate analytical method to be used for an extractor which can comply with ASME code. An extractor is designed using equivalent pressure vessel method by using ASME codes and its attachments, standard and non-standard, are designed using basic design concepts. The finite element analysis (FEA) is used to predict levels of stress and deflection of an extractor. These FEA results are compared with ASME allowable limit and are on safe side. The analytical design method is approximate method which results on positive error side.

\section{Supercritical Fluid Extraction}

Extraction process is basically for separation of one component from other component by using extracting solvent. In conventional process, the products so obtained from plants are relatively impure liquids, semisolids or powders intended only for oral or external use. So extraction continues to be of considerable interest in order to obtain improved yields of valuable constituent derived from plant and animal sources. Supercritical fluid extraction is the most effective and efficient way to extract valuable constituent botanicals. It is the process of separating one component (the extractant) from another (the matrix) using supercritical fluids that is $\mathrm{CO}_{2}$ as the extracting solvent. Process flow - $\mathrm{CO} 2$ reservoir contains the liquid $\mathrm{CO} 2$ at high pressure. The liquid $\mathrm{CO} 2$ is pumped through a heat exchanger to reach the system at supercritical stage, after the $\mathrm{SC}-\mathrm{CO} 2$ is uniformly pumped in the Extractor where dry and ground plant material forms a bed of solid matrix. During extraction, the supercritical solvent passes through the plant matrix bed and dissolves the soluble compounds. The mixture solvent-plant solutes is separated in separator usually changing drastically the solvent power of $\mathrm{CO} 2$ by depressurization using relief valves. Then $\mathrm{CO} 2$ is cooled at liquid state and compressed to return to the extractor.

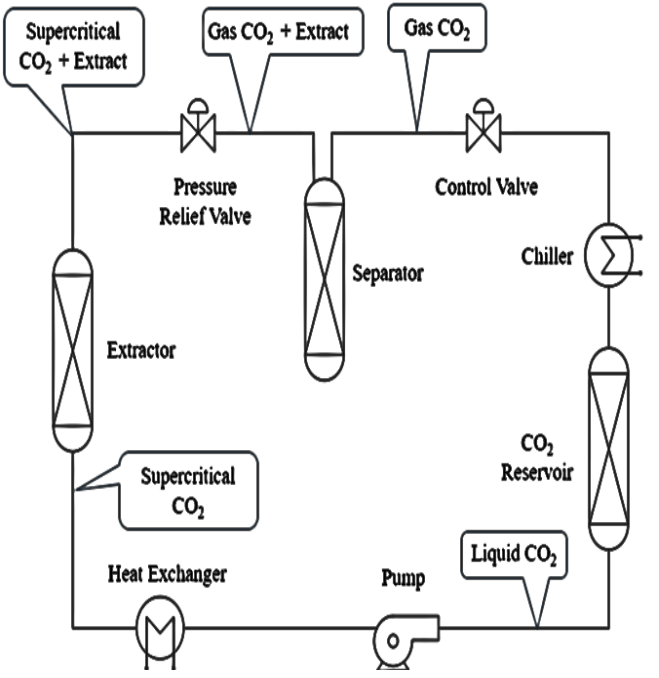

Fig. 1: Extraction Process Unit

\section{Extractor Design}

The objective of extractor designed here is to extract essential oil from Holy Basil (Tulsi) leaves using an extraction unit working with supercritical fluid under a specific range of high internal pressure and moderate temperature. The extraction unit is mainly used in chemical, food and pharmaceutical industries to extract not only most of the perfume or flavour materials but also waxes, colouring matter and essential oils from plant material. Mostly these extraction unit works with a very high pressure but with different volume.

Extractor consists of following components:

A) Main Shell: It is the pressure vessel which contains the natural botanical; here holy basil (Tulsi) leaves, from which essential oil is to be extracted.

B) Cap: This is one of the main component of top end closure. There are provisions for fitting a PRV and out vent for extract and $\mathrm{CO}_{2}$ mixture.

C) Cap Seating Cover: It serves the seating arrangement for cap and it is welded to the main shell as shown in Fig.2.

6th National Conference RDME 2017, 17th-18th March 2017.

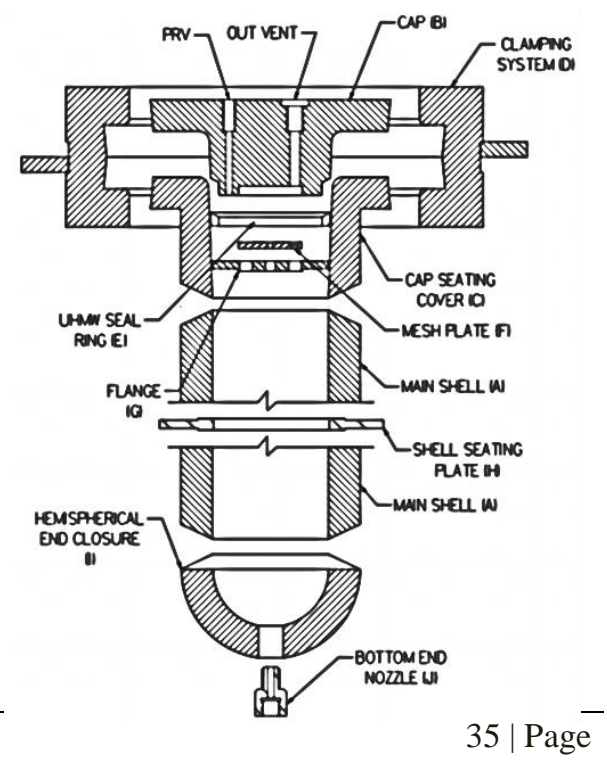

DOI: $10.9790 / 1684-17010043341$ 
D) Clamping System: It is nothing but the quick relief system. It has two halves, each having one end hinged and other is locked with locking pin. Locking pin is removable so that clamping system can Assembly be operated.

E) $U H M W$ Seal: Ultra-high-molecular-weight polyethylene Seal is used here. Whenever pressure is going to increase this seal expands and serves leak-proof condition. It is fitted at the bottom of cap, inside the cap seating cover.

F) Mesh Plate: This plate is fitted at the bottom side of cap. Mesh plate performs the function of filtration. It allows only the mixture of extract and $\mathrm{CO}_{2}$ to pass through it.

G) Flange: It is intermediate plate which connects mesh plate with cap.

H) Shell Seating Plate: It is used for mounting of an extractor on designed frame.

I) Hemispherical End Closure: It is bottom end closure welded to the main shell using seam welding.

J) Bottom End Nozzle: It is the input port of an extractor. Supercritical $\mathrm{CO}_{2}$ enters into the vessel through bottom end nozzle.

So for particular range of pressure with specified volume, a systematic procedure to design an extractor may become useful.

\subsection{Forces Acting on Extractor}

An extractor is subjected to a very high internal pressure, due to which stresses are developed on the walls of extractor as well as on top assembly. The longitudinal stresses and shear stresses developed in an extractor and top assembly are shown in Fig. 3 and 4 respectively.

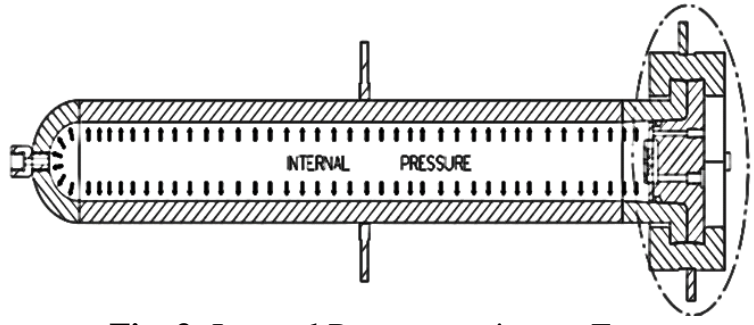

Fig. 3: Internal Pressure acting on Extractor

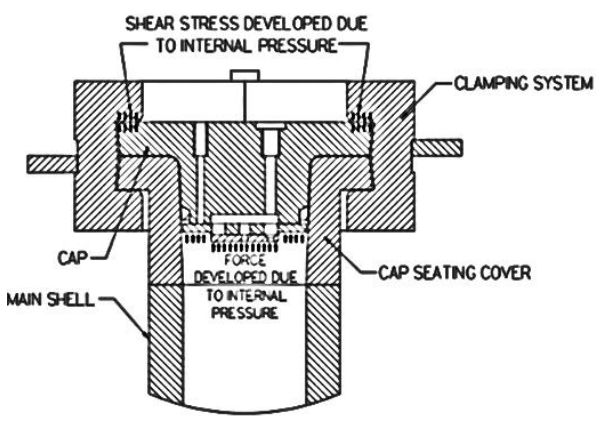

Fig. 4: Forces acting on Top Assembly

When $35 \mathrm{MPa}$ pressure is applied in an extractor through supercritical $\mathrm{CO}_{2}$, longitudinal stress are developed. Each and every component of an extractor undergoes the stress developed due to this high internal pressure. In case of top assembly, cap seating cover also experiences an internal pressure. Due to high pressure, cap tries to lift up, but as there is a provision of clamping system, it remains at its position. But at this moment, holdingand-releasing forces are acting along the fibres at the contact area of clamps and cap and cap seating cover in a tangential direction which results into the shear stresses acting along those fibres where this forces are acting. At bottom section, hemispherical end closure undergoes an internal pressure which is applied through supercritical $\mathrm{CO}_{2}$. As bottom end nozzle is the input through which supercritical fluid enters into the extractor experiences a very high pressure. Maximum stresses get developed at this nozzle section only. All the forces mentioned above are considered while designing an extractor. A pressure vessel is designed on the basis of internal pressure criteria as per the ASME Code Section VIII Div.I. Also, the hemispherical end closure and bottom end nozzles are designed using ASME Code Section VIII Div.I. The standard and non-standard components in a top assembly are designed by using fundamental design concepts. This work develops a systematic approach for design of an extractor working with a supercritical fluid under a very high internal pressure. 


\subsection{Input Parameters for Design}

The working parameters needed for design of extractor are as given in table 1 .

Table 1 Input Parameters for Extractor Design

\begin{tabular}{|l|c|c|c|}
\hline \multicolumn{1}{|c|}{ Parameter } & Label & Value & Unit \\
\hline Working Pressure & $\mathrm{P}_{\mathrm{w}}$ & 35 & $\mathrm{MPa}$ \\
\hline Design Pressure & $\mathrm{P}$ & 41.5 & $\mathrm{MPa}$ \\
\hline Working Temperature & $\mathrm{T}_{\mathrm{w}}$ & 63 & ${ }^{\circ} \mathrm{C}$ \\
\hline Volume of Extractor & $\mathrm{V}$ & 5 & Lit \\
\hline Weld Joint Efficiency & $\mathrm{E}$ & 0.85 & - \\
\hline
\end{tabular}

\subsection{Material of construction}

Pressure vessels form a major part of the equipment used in the chemical, food and pharmaceutical industries. It is therefore, desirable to consider the suitability of the different materials for construction of pressure vessels operating under different conditions Here, the material required for standard component is selected as per the application of food-grade and as per the operating pressure and temperature condition to which it is subjected and the form of the material.

\section{1) Extractor Material:}

The material used for extractor is stainless steel of grade SS-316. Material properties are as shown in table 2. The maximum allowable stress value is the maximum unit stress permitted in a given material used in a vessel constructed. The criteria for maximum allowable tensile stress values permitted for different materials are as per the ASME Code Section II Part D Subpart 3. As per it, the allowable stress value for selected extractor material is 170 $\mathrm{MPa}$.

Table 2: Mechanical Properties of Extractor Material

\begin{tabular}{|l|c|c|}
\hline \multicolumn{1}{|c|}{ Parameter } & Value & Unit \\
\hline Selected Material & SS-316/ 316L & \\
\hline Nominal Composition & 16Cr 12Ni 2Mo 0.08C & - \\
\hline Product Form & Seamless Pipe/ Rods & - \\
\hline Size / Thickness & - & $\mathrm{mm}$ \\
\hline UNS No. & S31600/31603 & - \\
\hline Tensile Strength & 485 & $\mathrm{MPa}$ \\
\hline Allowable Yield Strength & 170 & $\mathrm{MPa}$ \\
\hline Max. Temperature limit & 454 & ${ }^{\circ} \mathrm{C}$ \\
\hline Density & 7870 & $\mathrm{~kg} / \mathrm{m}^{3}$ \\
\hline Modulus of Elasticity & 193 & $\mathrm{GPa}$ \\
\hline Shear Stress & 152.9837 & $\mathrm{MPa}$ \\
\hline
\end{tabular}

Table 3: Mechanical Properties of Extractor Material

\begin{tabular}{|l|c|c|}
\hline \multicolumn{1}{|c|}{ Parameter } & Value & Unit \\
\hline Max operating pressure & 83 & ${ }^{\circ} \mathrm{C}$ \\
\hline Melting Temperature & 136 & ${ }^{\circ} \mathrm{C}$ \\
\hline Flexural Modulus & 758 & $\mathrm{MPa}$ \\
\hline Linear expansion & 13 & $/{ }^{\circ} \mathrm{C} * \mathrm{E}-5$ \\
\hline Density & 951 & $\mathrm{~kg} / \mathrm{m}^{3}$ \\
\hline Tensile strength & 35 & $\mathrm{MPa}$ \\
\hline Modulus of elasticity & 827 & $\mathrm{MPa}$ \\
\hline Water absorption & 0.01 & $\%$ \\
\hline
\end{tabular}

\section{2) Seal Material:}

Material used for seal which is fitted to the bottom of cap is Ultra-high-molecular-weight-polyethylene type (UHMWPE). We have referred a catalogue of BRASKEM for it. It has extremely long chains which serve to transfer load more effectively by strengthening intermolecular interactions resulting a very tough material. It has highest impact strength and it is resistive towards chemical agents. Also this material has extremely low moisture absorption. It shows self-lubricating and self-adjustment for sealing type property. Coefficient of friction for this material is significantly lower. Other properties of UHMWPE are it is odourless, tasteless and non-toxic. Properties are shown in table 3 .

\subsection{Design by Formula (Analytical Method)}

The manual design of an extractor is done by following ASME codes and basic machine design concepts. As per ASME codes the design procedures are mentioned by considering factor of safety as 3.5.The manual design of an extractor considers only stresses developed due to internal pressure P. The stresses developed due to friction at 
contacting surface between two components are ignored. Also the loads transmitted by supports, seismic loads, wind loads are not considered as in this case the height of pressure vessel is less than $1 \mathrm{~m}$.

A) Main Shell:

Main shell of an extractor is designed by following ASME Codes Section VIII Div. I. As per it, to design a pressure vessel under internal pressure must satisfy either circumferential stress (longitudinal joints) or longitudinal stress (circumferential joints). In this case as we are selecting seamless pipe, it doesn't have longitudinal joints hence design is based on longitudinal stress (circumferential joints). Also the criteria of longitudinal stress that is $\mathrm{P}<1.25 \mathrm{SE}$ is satisfied with given input parameters. The thickness of shell designed by using following formula is calculated as $26 \mathrm{~mm}$ for the diameter of $141.3 \mathrm{~mm}$ as per All Metal India Pvt. Ltd. Catalogue which is used for selection of standard sizes of seamless pipe.

$$
t_{1}=\frac{P R}{2 S E+0.4 P}
$$

B) Cap Seating Cover:

The holding-and-releasing forces are acting along the fibres at the contact area of clamps and cap and clamps and cap seating cover in a tangential direction which results into the shear stresses acting along those fibres where this forces are acting. The thickness at this fibre section, following steps to be used which are based on basic design concepts. Thickness of cap seating cover is calculated as $17.64 \mathrm{~mm}$ but for required application we need to increase this thickness up to $26 \mathrm{~mm}$ so that it can easily be welded to main shell.

$$
\tau=\frac{F}{\pi D_{3} t_{2}}
$$

C) Cap:

Top end closure is a modified end closure as per the requirement of an application. It is the modification of torispherical end closure, hence by using torispherical head design procedure the thickness of cap can be found out. It is calculated as $37.29 \mathrm{~mm}$ approximated to $38 \mathrm{~mm}$.

$$
t_{3}=\frac{0.885 P L}{S E-0.1 P}
$$

D) Clamping System:

Clamping system is the quick release system for an extractor. This is the new development for an extractor for opening and closing purpose. As when internal high pressure is applied, shear stresses are developed at the contact surface of clamp and cap. Based on machine design concepts, thickness of clamping system is calculated as $18.69 \mathrm{~mm}$ approximated to $20 \mathrm{~mm}$.

$$
\tau=\frac{F}{\pi D_{5} t_{4}}
$$

E) Hemispherical End Closure:

By referring ASME Codes, hemispherical end closure is designed and thickness of it is calculated as $25.12 \mathrm{~mm}$ approximated to $26 \mathrm{~mm}$.

$$
t_{5}=\frac{P L}{2 S E-0.2 P} \text {. }
$$

F) Bottom End Nozzle:

This is the weakest portion of pressure vessel or it is, where maximum stress is going to be developed due to internal pressure as it is the input provision through which a high pressurised supercritical fluid is entered into the extractor. By using ASME codes, nozzle can be designed. Also for verification one can use machine design concepts. The thickness of nozzle is calculated as $15.26 \mathrm{~mm}$ approximated to $16 \mathrm{~mm}$.

$$
t_{n}=\frac{P R}{S E-0.6 P} .
$$

\section{Safety Precautions}

An important responsibility of a pressure vessel designer is to ensure that a plant under design can be operated safely. One of the hazardous situations that can arise during operation is when a system is subjected to a pressure higher than that for which it was designed. Therefore, pressure relief systems are needed to protect personnel and equipment from the undesirable consequences of excess pressure. In this work, an extractor undergoes a high pressure hence it is necessary to make some provisions for safety.

1) Rupture Disk:

It is a non-reclosing pressure relief device to protect the pressure vessel from over-pressurization. It is a sacrificial part because it has one time use membrane that fails at predetermined pressure. If the pressure relief valve fails to 
operate and pressure is increasing then rupture disk will burst and pressure get released. By referring BS \& B catalogue a rupture disk is selected having following specification.

\begin{tabular}{|c|c|c|c|c|c|}
\hline Disk Size & $\begin{array}{c}\text { Burst } \\
\text { Pressure }\end{array}$ & $\begin{array}{c}\text { Loading } \\
\text { (Direction of flow) }\end{array}$ & Material & $\begin{array}{c}\text { Service } \\
\text { phase }\end{array}$ & Temp \\
\hline $141 \mathrm{~mm}$ & $400 \mathrm{bar}$ & SS 316 & $\begin{array}{c}\text { Gas or } \\
\text { Liquid }\end{array}$ & $45^{\circ} \mathrm{C}$ \\
\hline
\end{tabular}

\section{2) Pressure Relief Valve}

The pressure relief valve is a type of control or limits the pressure in a system working with high pressure. These relief vale are designed or set to open at a predetermined pressure to protect a pressure vessel. Whenever a pressure exceeds the operating condition of pressure, relief valves get open and provide a least resistance path to release pressure. By referring Swagelok catalogue a manual override handle type pressure relief valve of R3ASeries is selected. Predetermined pressure is set at 400bar.

\section{Finite Element Analysis}

The CAD modelling of an extractor is carried out in Solid Edge ST8 software and analysis is done by ANSYS 16.0. Top assembly and nozzle opening on shells are important for inspection. These are the weakest areas where stress concentration likely to occur. So the joint is most vulnerable part to failure. It's of great importance to study the influence of various parameters on stress distribution of an extractor. Due to internal pressure loadings applied inside the shell, a local stress state of the extractor and its connection can be characterized using FEA. This analysis is carried out in two section, first for main shell assembly in which main shell and nozzle are analysed, second section is of top assembly in which cap, cap seating cover, flange, mesh plate and clamping system are analysed.

\subsection{Analysis}

a) Basic Assumptions:

In order to simplify the analysis of an extractor, a number of assumptions were made. These basic assumptions are:

- Sealing material was assumed to have linear properties with the non-linear behavior of the seal section ignored.

- All materials used for main shell, nozzle, end closures, top assembly components are assumed isotropic.

- Analysis will be linear static analysis.

- Temperature effects will not be considered.

\section{b) Structural Analysis}

1) Main Shell:

In case of main shell assembly, the fixed supports are applied at shell seating plate which is going to be rest on a frame and at the bottom side of nozzle. For structural analysis, meshing and loading conditions are important. Main shell assembly is meshed with solid tetrahedron elements with fine mesh size of $5 \mathrm{~mm}$. Internal pressure of $41.5 \mathrm{MPa}$ act as a loading condition which should be applied inside the shell and at the nozzle section. A Von-Mises stress distribution on main shell assembly is shown in Fig. 5. 


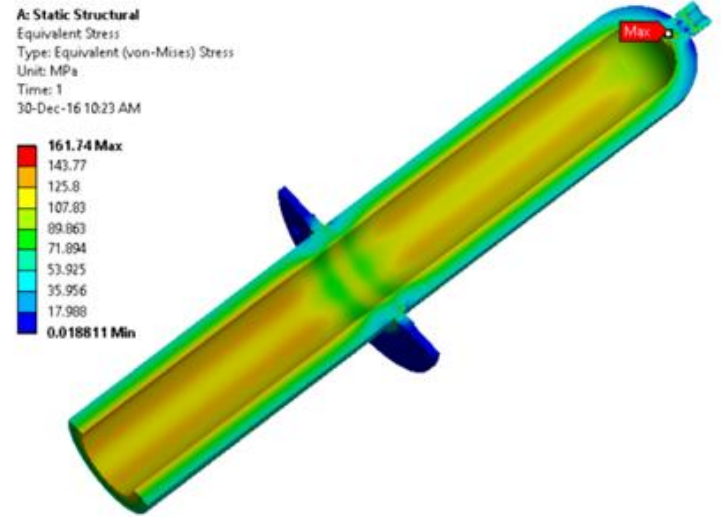

Fig. 5: Von-Mises Stress Distribution (Sectional View)

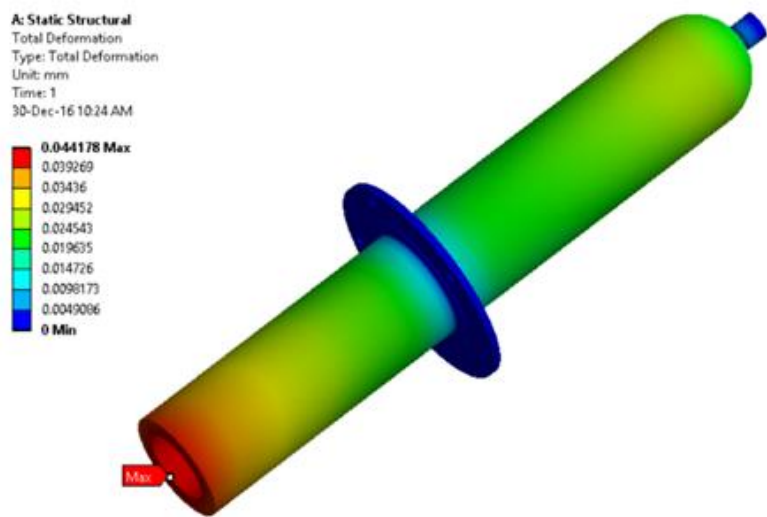

Fig. 6: Deformation of Main Shell

\section{2) Top Assembly:}

In case of top shell assembly, the fixed supports are applied at bottom side of cap seating cover which is welded to the main shell. Top assembly is meshed with solid tetrahedron elements with fine mesh size of $5 \mathrm{~mm}$. Internal pressure of $41.5 \mathrm{MPa}$ act as a loading condition which should be applied inside the cap seating cover, at the surface of cap, mesh plate, flange, cap and clamping contact and through the out vent. A Von-Mises stress distribution on top assembly is shown in Fig. 7.

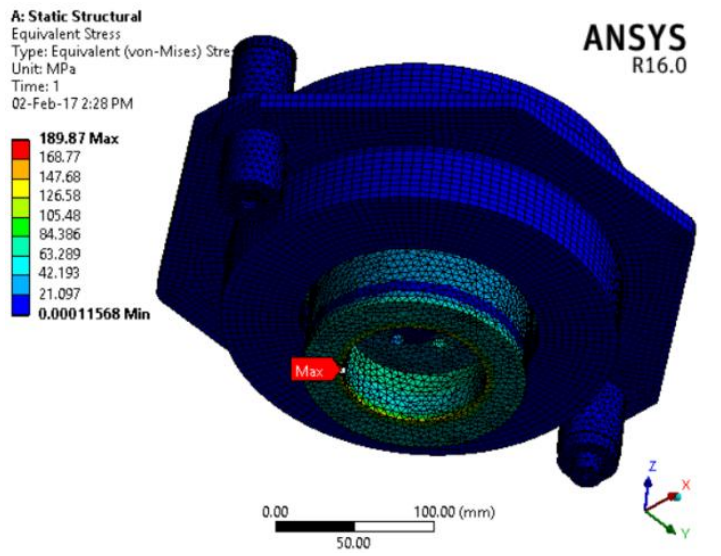

Fig. 7: Sectional view of Von-Mises stress Distribution

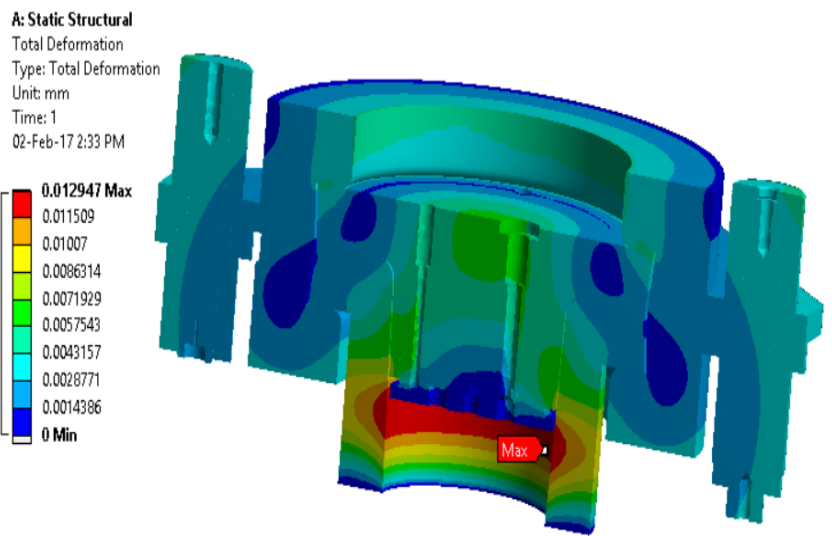

Fig. 8: Deflection of Top Assembly

\section{c) Results:}

The von Mises stress plots of main shell assembly analysis is shown in Fig. 5. The maximum stress generated is $161.74 \mathrm{MPa}$. This stress value is below the yield strength of material. The stresses are localized at nozzle section as shown in stress distribution fig 5. The stress in the other regions is within allowable limit.

The deformation plot of main shell assembly subjected to given loading conditions is as shown in Fig. 6 . The maximum deformation obtained is $0.044 \mathrm{~mm}$ in the top portion of shell. Maximum deformation occurring in flange is within the allowed range that is $2 \mathrm{~mm}$; so the design is safe for deformation \& also deformation is negligible as compared to overall size of the main shell. The von Mises stress plots of top assembly analysis is shown in Fig. 7. The maximum stress generated is $189.87 \mathrm{MPa}$. This stress value is below the yield strength of material. The stresses are localized at bottom section as shown in stress distribution Fig. 7. The stress in the other regions is within allowable limit. The deformation plot of top assembly subjected to given loading conditions is as shown in Fig. 8. The maximum deformation obtained is $0.012947 \mathrm{~mm}$ in the top portion of clamping system. Maximum deformation occurring in flange is within the allowed range that is $2 \mathrm{~mm}$; so the design is safe for deformation \& also deformation is negligible as compared to overall size of the top assembly. 


\section{Conclusions}

The design of an extractor has been done analytically and its finite element analysis has been conducted which shows the equivalent stresses generating in extractor. The key conclusions are as listed below-

- The systematic design procedure explained for designing a high pressure vessel with its end closure which also complies the ASME codes is suitable for extractor.

- The stress values calculated using with this method falls on the high side than FEA results as required for a safe design.

- The stress concentration in extractor is maximum at the top area of pressure vessel and in case of top assembly it is at clamping system.

- Though it is an approximate method, it can be used successfully to design an extractor for various range of pressure and temperature.

- The limitation for this method is it may require designing more suitable size for clamping system. As it is mounted on a special purpose designed end closure, its size and shape may require modification as the application changes.

\section{References}

[1] Andrea Capuzzo, Massimo E. Maffei and Andrea Occhipinti, "Supercritical Fluid Extraction of Plant Flavors and Fragrances", MDPI* : molecule, 2013, 18, 7194-7238;

[2] Mandana Bimakra,*, Russly Abdul Rahmana,b, Farah Saleena Taipa, Ali Ganjloob, Liza Md Salleha,d, Jinap Selamatc, Azizah Hamidc, I.S.M. Zaidulc, "Comparison of different extraction methods for the extraction of major bioactive flavonoid compounds from spearmint (Mentha spicata L.) Leaves", Food And Bioproducts Processing 89 (2011) 67-72.

[3] C. Pronyk, G. Mazza, "Design and scale-up of pressurized fluid extractors for food and bio-products", Journal of Food Engineering 95 (2009) 215-226

[4] Frank Panzner, Braib R. Evans, "Extraction of plant material by using carbon dioxide", United States Patent, November 1985.

[5] G. N. Sapkale, S. M. Patil, U. S. Surwase And P. K. Bhatbhage. "Supercritical Fluid Extraction", Int. J. Chem. Sci.: 8(2), $2010,729-743$.

[6] Vibha Porwal, Pallavi Singh, Devendra Gurjar, "A Comprehensive Study On Different Methods Of Extraction From Guajava Leaves For Curing Various Health Problem", International Journal of Engineering Research and Applications, Vol. 2, Issue 6, November-December 2012, pp.490-496

[7] M. Angela, A. Meireless, "Supercritical extraction from solid: process design data", Current opinion in solid state and material science Elsevier Ltd., 2003, 7 (2003) 321-330.

[8] Nitin Deshmukh, Rajkumar Patil, "Design and analysis of Pressure vessel", International Journal of Innovative Research in Technology and Science, 2013. Volume 2(3), 28-34.

[9] Tang Deyu, Niu Huli, Li Chunrun, Fang Zongtao, LvTao, ZhaoJie, "A Whole Fatigue Analysis Design about High Pressure Quickopen Vessels on ANSYS", International symposium on Instrumentation \& Measurement, sensor Network \& Automation China, 2012, Vol. 2, 25-28.

[10] "Rules for Construction Of Pressure Vessels", ASME Boiler and Pressure Vessel Code 2010: Section VIII Division 1 (2010).

[11] ASME BPVC section VIII Division-2, "Alternative Rules for Construction of Pressure Vessels", 2013, ASME International.

[12] ASME BPVC section II Part D, "ASME Boiler and Pressure Vessel Code - Materials (Metric)”, ASME International.

[13] ASME PTB-3, "ASME BPVC section VIII- Division 2 Example Problem Manual”, 2013, ASME International.

[14] Guibing Zhao, "An easy method to design gas/vapor relief system with rupture disk", Journal of Loss Prevention in the Process Industries Elsevier Ltd., Volume 35, May 2015, Pages 321-328. 